\title{
Analysis of the cognitive aspects of elderly people considering the practice of regular physical exercises and associated factors
}

Thuane Lopes Macedo' (ID) Rafael Cunha Laux ${ }^{2,3} \mathbb{D}$ Alice Arruda Londer $0^{3} \mathbb{D}$ Sara Teresinha Corazza ${ }^{1,3}$ (D)

\section{Abstract}

Objective: The objective of this study was to compare the cognitive performance of elderly who are enrolled in a physical activity (PA) program with those who are not, considering some sociodemographic variables that are related to the practice of cognitive activities. Method: 59 elderly people participated in this study divided into control group (CG) and gymnastics group (GG). The Vienna Test System $^{\circledR}$ was used to estimate the attention and concentration capacities, simple reaction time and peripheral perception. To test the normality of the data it was used the Shapiro Wilk Test. The association between PA and socioeconomic variables was verified by Chi-Square Test and Fisher Exact Test. To compare of differences between groups the Mann Whitney U-test for variables with non-parametric distribution and the Student T-test for independent samples for other variables were used. Result: There were no significant differences in the performance of the groups, except in the capacity of attention and concentration in which CG presented best performance $(p=0.01)$. Factors as schooling $(p=0.02)$, income $(p=0.001)$ and regular practice of handcrafts $(p=0.06)$ can explain the best performance of CG. Conclusion: This study found no evidence that the practice of physical activity can generate some cognitive benefit in the elderly when compared to the elderly who did not practice regular physical activity. However, we perceive the existence of other aspects that influence on the cognition, such as schooling, sociocultural level and the reading habit, that have a significant importance degree in the analysis.

\footnotetext{
Universidade Federal de Santa Maria, Programa de Pós-graduação em Gerontologia. Santa Maria, Rio Grande do Sul, Brasil.

2 Universidade do Oeste de Santa Catarina, Curso de Educação Física. Chapecó, Santa Catarina, Brasil.

3 Universidade Federal de Santa Maria, Programa de Pós-Graduação em Educação Física. Santa Maria, Rio Grande do Sul, Brasil.
}

\section{Keywords: Aging.}

Reaction Time. Attention.

Psychomotor Performance.

Visual Acuity. 


\section{INTRODUCTION}

Senescence brings with it cognitive limitations resulting from changes in the central nervous system, reduced nerve conduction and sensory perception that interfere with executive function and psychomotor performance ${ }^{1,2}$. The search for evidence that optimizes the use of non-pharmacological strategies in an attempt to mitigate these alterations has gradually increased ${ }^{3,4}$. Evidence suggests that a high level of regular physical activity is associated with better physical, motor and cognitive performance, reducing the risk of cognitive decline and dementia in adulthood ${ }^{5}$. However, the mechanisms of relationship between physical exercise and cognitive functioning in the elderly are still not well understood ${ }^{6}$.

Cognitive processes such as focused attention, reaction time, and peripheral perception are extremely important for the day to day life of the elderly. They are directly related to the ability to focus attention on the relevant stimuli of the environment ${ }^{7}$ as well as respond quickly to environmental stimuli ${ }^{1}$ and perceive the environment around them through spatial orientation in order to avoid possible accidents and perform daily activities with effectiveness ${ }^{8}$. Therefore, further clarification on the importance of physical activity in cognitive aspects becomes important in order to elucidate possible intervention strategies against the cognitive decline of older people.

According to the conclusions of Bherer, Erickson, Ambrose $^{2}$, physical activity is a promising nonpharmaceutical intervention to prevent cognitive decline related to age and neurodegenerative diseases, mainly due to the improvement of cardiorespiratory capacity. Freudenberger et al. ${ }^{9}$ also add that better cardiorespiratory fitness is highly related to better performance in the cognitive domains of memory, executive function and motor skills in middleaged and elderly individuals. However, a recent literature review ${ }^{10}$ did not find significant evidence between aerobic physical activity and cognitive function improvement in the elderly without known cognitive impairment. These findings corroborate Desjardins-Crépeau et al. ${ }^{11}$ who also argue that not all executive/mental functions are improved with physical activity. For a better understanding of the relation of physical activity to cognitive conditions this study was structured, which compared the cognitive performance of practicing and nonregular physical activities adults, considering some sociodemographic variables and related to the practice of cognitive activities.

\section{METHOD}

For the formation of the active elderly group, gymnastic practitioners (GG) from groups linked to the Integrated Nucleus of Studies and Support to the Third Age (INSSTA) of the Universidade Federal de Santa Maria (UFSM) were invited to participate in the research. In order to minimize the possible performance differences caused by different stimuli, only groups that practiced classes with the same teacher were selected. Thus, a total of 200 elderly people practicing three INSSTA gymnastics groups were invited to participate in the study. The gym classes were held twice a week, lasting 50 minutes. Normally, classes were subdivided into warming up (dancing in pairs) and stretching; main part with choreographed dances, coordinating exercises for upper and lower limbs and / or functional circuits; finally, the overall stretching in groups or individual. The level of physical effort during class was not measured.

For the formation of the elderly group, those who did not practice physical activity, called control group (CG) were invited to participate in the research, elderly people living in the same neighborhoods of the active elderly, indicated by the GG participants. There was also a publicizing in the media through publication in newspapers and digital media.

A group of 63 elderly people was interviewed in the gymnastic group; from this group, 17 individuals were excluded because they did not reach the minimum score in the MMSE, eight individuals due to uncorrected auditory or visual problems, four individuals had a greater percentage of absences than allowed, four individuals practiced another PA and one person could not complete the battery of tests due to difficulties in manipulating the computer. In the control group, 50 elderly people were evaluated, among them eight were excluded in the MMSE, 
seven were classified as active in the IPAQ and five presented uncorrected auditory or visual problems.

Thus, after interview, and according to the criteria of inclusion and exclusion of the study, the GG group was composed of 29 elderly people with a mean age of $69.43( \pm 4.63)$ years. In CG, the group had 30 participants, with a mean age of $69.93( \pm 5.05)$ years. It is understood that chronological age influences cognition in general, so the groups were classified into age groups, arranged in Gymnastic group 1 (GG1, n=17, for participants aged 60-69 years) and Gymnastic group 2 (GG2, n=12, for participants aged 70 to 79 years). The same division by age group was done with the Control Group by dividing it into Control Group $1(\mathrm{GC1}, \mathrm{n}=15)$ and Control Group $2(\mathrm{GC} 2, \mathrm{n}=15)$.

For the formation of the GG, elderly people aged between 60 and 79 years of both sexes, effective participants of the gym classes in the groups referred for at least six months were invited to participate in the research. In addition, the practice frequency of the exercise was established as twice a week, with a minimum frequency of $75 \%$ of classes in the evaluation semester. For the CG, elderly people of the same age group were invited to participate in the study, who declared that they did not practice any regular physical activity for at least six months classified as insufficiently active or sedentary according to the International Questionnaire of Physical Activity $(\mathrm{IPAQ})^{12}$, according to classification of $\mathrm{WHO}^{13}$.

Participants with physical and / or cognitive impairment, who could alter the study's evaluation variables were excluded, they were verified through an interview and by the Mini Mental State Examination ${ }^{14}$, adapted to the Brazilian population by Brucki et al. ${ }^{15}$, according to schooling. As well as visual sensorial deficit diagnosed through the Snellen Sign Scale, according to the Ministry of Health's indication ${ }^{16}$. In order to track possible auditory sensorial deficits, the whisper test ${ }^{17}$ was applied, and participants were asked if they had serious hearing problems and / or hearing difficulty. People who declared that they had other physical activity, had diseases with decreased vision or had previous history of stroke, Parkinson's disease and Alzheimer's were also excluded.
Socioeconomic situation, health conditions, history of falls and cognitive stimulation were evaluated by means of a questionnaire, duly constructed for this research, in the form of an interview.

The Vienna Test System ${ }^{\circledR}$ software (VTS), Version 6.81 .013 was used to estimate attention and concentration (COG), simple reaction time (SRT) and peripheral perception (PP). The tests used had an animated instruction phase and a training phase with error feedback, allowing the examinee to familiarize himself/herself with the test and ensure an understanding of the task. The two evaluators who carried out the research first went through a training process, a pilot project, in which 12 INSSTA practitioners of water aerobics were evaluated in two different moments. No significant differences were found between the results of the researchers.

In order to measure the cognitive profile of the participants, the Cognition Test (COG) version S7 $7^{18}$ was used. The test evaluates the general skills of cognition and is used to measure attention levels and concentration by comparing figures relatively to their similarity. The task of the examinee was to compare an isolated figure with a model block, and to evaluate its similarity. For equal figures the evaluated should press the green key, and for different figures should press the red key as fast and correct as possible. A total of 100 figures were presented, 50 being equal and 50 different to the model block. As a result, the number of correct rejections and the mean time (in seconds) taken to answer the comparisons were taken.

The analysis of the capacity of the simple reaction time (SRT) happened through the RT Test version S1, for SRT with visual stimulus, and RT Test version S2, for SRT with auditory stimulus ${ }^{19}$.

The analysis of the simple reaction time (SRT) happened through version S1 (with visual stimuli) and version S2 (with auditory stimuli). The task was to hold the index finger of the hand preferably under a rest key and, whenever the stimulus, yellow circle or high-pitched tone is displayed, press a preset key as fast as possible. 28 stimuli were presented in each version of the test. For evaluation, the pre-motor and motor reaction time, given in milliseconds, were used. 
In order to measure peripheral vision, the Peripheral Perception Test (PP $)^{20}$ was used. The PP consists of two partial tasks: the task of perceiving lateral stimuli pertaining to peripheral perception itself, and a central tracking task aimed at focusing the attention of the examinee to the center of the visual field and investigating the ability of the evaluated to distribute his/her attention. The examiner was asked to step on the pedal with his/ her right foot whenever he/she recognized light stimuli on the right or left side of the panel but keeping a target close to a ball that moved on the monitor screen. 80 stimuli were presented, 40 on the left side and 40 on the right side, admitting a maximum field of view of $180^{\circ}$. As a result, the total visual field, in degrees, and the tracking drift in unmeasured unit were used. The image below (figure 1) illustrates the STV.

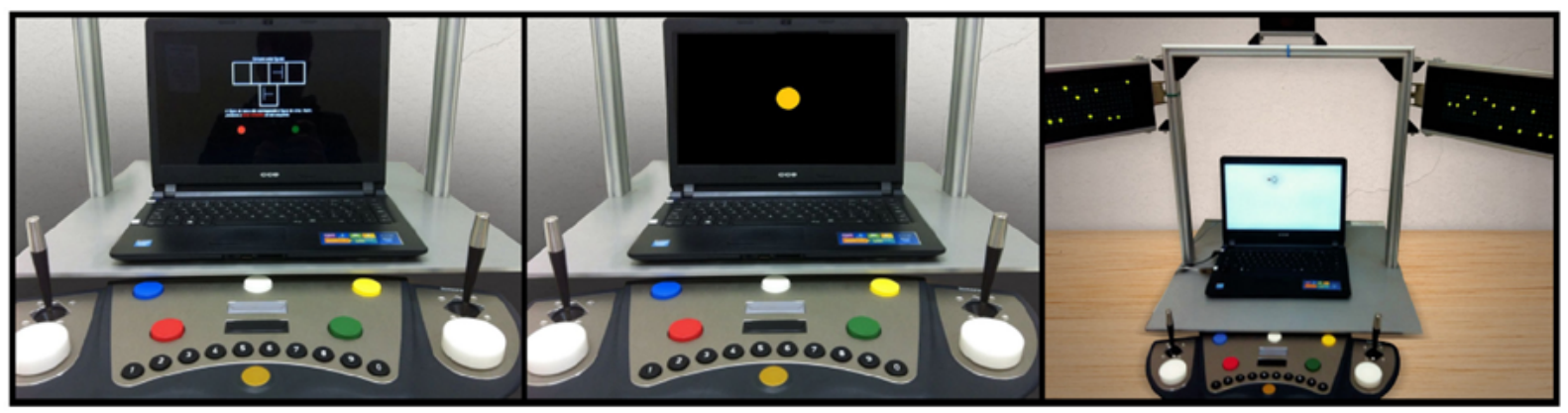

The image represents the cognitive, reaction time and peripheral perception tests, from the left to the right respectively.

Figure 1. Presentation of applied tests of the Vienna Test System ${ }^{\circledR}$. Santa Maria, Rio Grande do Sul, 2016-2017.

Descriptive statistics were applied to the variables mean, median, standard deviation and interquartile difference. To test the normality of the results, the Shapiro Wilk Test was used. In order to verify the association between physical exercise and socioeconomic variables, health conditions, history of falls and cognitive stimulation, a measure of statistical significance was used for categorical variables. The chi-square test was used for the variables falls and manual work, of the groups between 60 and 69 years. Also, for the variables: marital status, income and comorbidities of the groups with ages between 70 and 79 years. For the others, the Fisher exact test was used. In the comparison of the differences between groups, the Mann Whitney U test was used for variables with non-parametric distribution (in the elderly group between 60 and 79 years old - Premotor reaction time for visual stimulus and tracking deviation). And, in the elderly group, aged 70 to 79 years, pre-motor reaction time, for auditory stimulus, motor reaction time, for auditory stimuli and tracking deviation. In the other variables, which presented parametric distribution, the Student's T-test was used for independent samples. All analyzes were performed using SPSS software version 20.0 for Windows, adopting a significance level of $5 \%$.

This study presents, as ethical guidance, the requirements of Resolution 466/12 of the National Health Council, which regulates research involving human beings. The research began after approval of the Research Ethics Committee of UFSM and signing of the Term of Free Consent by the participants with opinion of approval $\mathrm{n}^{\circ} 1.154 .499$ ).

\section{RESULTS}

The socioeconomic characteristics, health conditions, history of falls and cognitive stimulation of the studied groups, stratified by age, are presented in Table 1. The variables schooling, family income and regular practice of manual work are highlighted with prevalence in the CG.

The IPAQ questionnaire was used to classify the level of physical activity of the elderly evaluated. A summation of the usual one-week physical activity practice time was made in the four domains of 
the instrument. All the elderly individuals of the gymnastic groups were classified as active / very active. In CG1, three people were classified as sedentary, and in CG2 two people were classified as being sedentary, the rest of the participants in the control groups were classified as poorly active.

Table 1. Socioeconomic information, health conditions, history of falls and cognitive stimulation through absolute and relative frequency of the elderly ( $\mathrm{n}=59)$. Santa Maria, Rio Grande do Sul, 2016-2017.

\begin{tabular}{|c|c|c|c|c|c|c|}
\hline Variables & $\mathrm{G} 1^{1}(\mathrm{n}=17)$ & $\mathrm{C} 1^{2}(\mathrm{n}=15)$ & $p^{*}$ & $G 2^{3}(n=12)$ & $\mathrm{C} 2^{4}(\mathrm{n}=15)$ & $p^{*}$ \\
\hline Age (years) & $66.159( \pm 2.263)$ & $65.666( \pm 3.000)$ & $0.806^{a}$ & $74.066( \pm 2.686)$ & $74.194( \pm 2.219)$ & $0.893^{a}$ \\
\hline \multicolumn{7}{|l|}{ Sex } \\
\hline Female & $16(94.118)$ & $11(73.334)$ & $0.161^{\mathrm{a}}$ & $4(33.333)$ & $14(93.333)$ & $0.002^{\mathrm{a}}$ \\
\hline Male & $1(5.882)$ & $4(26.666)$ & & $8(66.667)$ & $1(6.667)$ & \\
\hline \multicolumn{7}{|l|}{ Marital status } \\
\hline Withpartner & $4(23.530)$ & $7(46.667)$ & $0.266^{a}$ & $6(50.000)$ & $6(40.000)$ & $0.603^{\mathrm{b}}$ \\
\hline Withoutpartner & $13(76.470)$ & $8(53.333)$ & & $6(50.000)$ & $9(60.000)$ & \\
\hline \multicolumn{7}{|l|}{ Schooling } \\
\hline $\begin{array}{l}\text { Up to } 11 \text { years of } \\
\text { formal schooling }\end{array}$ & $13(76.470)$ & $7(46.667)$ & $0.144^{\mathrm{a}}$ & $12(100.000)$ & $9(60.000)$ & $0.020^{\mathrm{a}}$ \\
\hline $\begin{array}{l}12 \text { years or more of } \\
\text { formal schooling }\end{array}$ & $4(23.530)$ & $8(53.333)$ & & $0(0.000)$ & $6(40.000)$ & \\
\hline \multicolumn{7}{|l|}{ Occupation } \\
\hline Works & $4(23.530)$ & $7(46.667)$ & $0.266^{a}$ & $0(0.000)$ & $2(13.333)$ & $0.487^{\mathrm{a}}$ \\
\hline Doesn't work & $13(76.470)$ & $8(53.333)$ & & $12(100.000)$ & $13(86.667)$ & \\
\hline \multicolumn{7}{|l|}{$\begin{array}{l}\text { Family income } \\
\text { (salaries) }\end{array}$} \\
\hline Up to 3 & $11(64.706)$ & $1(6.667)$ & $0.001^{\mathrm{a}}$ & $5(41.667)$ & $7(46.667)$ & $0.795^{\mathrm{b}}$ \\
\hline More than 3 & $6(35.294)$ & 14 (93.333) & & $7(58.333)$ & $8(53.333)$ & \\
\hline \multicolumn{7}{|l|}{ Comorbidity } \\
\hline Up to 3 diseases & $14(82.353)$ & $9(60.000)$ & $0.243^{\mathrm{a}}$ & $7(58.333)$ & $7(46.667)$ & $0.547^{\mathrm{b}}$ \\
\hline More than 3 disease & $3(17.647)$ & $6(40.000)$ & & $5(41.667)$ & $8(53.333)$ & \\
\hline \multicolumn{7}{|l|}{ Use of medicines } \\
\hline Yes & $13(76.470)$ & $14(93.333)$ & $0.338^{\mathrm{a}}$ & $9(75.000)$ & $14(93.333)$ & $0.294^{\mathrm{a}}$ \\
\hline No & $4(23.530)$ & $1(6.767)$ & & $3(25.000)$ & $1(6.667)$ & \\
\hline \multicolumn{7}{|l|}{ Falls } \\
\hline Yes & $6(35.294)$ & $5(33.333)$ & $0.907^{b}$ & $1(8.333)$ & $3(20.000)$ & $0.605^{\mathrm{a}}$ \\
\hline No & $11(64.706)$ & $10(66.667)$ & & $11(91.667)$ & $12(80.000)$ & \\
\hline \multicolumn{7}{|l|}{ Handcrafts } \\
\hline Yes & $10(58.824)$ & $8(53.333)$ & $0.755^{\mathrm{b}}$ & $4(33.333)$ & $11(73.33)$ & $0.057^{\mathrm{a}}$ \\
\hline No & $7(41.176)$ & $7(46.667)$ & & $8(66.667)$ & $4(26.666)$ & \\
\hline \multicolumn{7}{|l|}{ Reading habit } \\
\hline Yes & $9(52.941)$ & $12(80.000)$ & $0.147^{a}$ & $4(33.333)$ & $11(73.33)$ & $1.00^{\mathrm{a}}$ \\
\hline No & $8(47.058)$ & $3(20.000)$ & & $8(66.667)$ & $4(26.666)$ & \\
\hline
\end{tabular}

${ }^{1}$ Gymnastics Group 1 (from 60 to 69 years); ${ }^{2}$ Gymnastics Group 2 (from 70 to 79 years); ${ }^{3}$ Control Group 1 (from 60 to 69 years); ${ }^{4}$ Control Group 2 (from 70 to 79 years); ${ }^{a}$ Fisher Test; ${ }^{\mathrm{b}} \mathrm{Chi}-$ Square test. 
In a second analysis we present the results obtained through the evaluation of cognitive and perceptive motor performance in the attention and concentration dimensions, simple reaction time (pre-motor) and motor time, for auditory and visual stimuli, peripheral perception and distributed attention capacity. The same distribution of groups was maintained. Table 2 shows the results of the tests and the comparison between GG and CG, which had similar performances, except for the number of hits, in the attention test, in which CG performed better $(p=0.01)$.

Table 2. Cognitive and perceptive motor performance of elderly in Santa Maria, Rio Grande do Sul, Brazil, 2016-2017.

\begin{tabular}{|c|c|c|c|c|c|c|}
\hline \multirow[t]{2}{*}{ Variables } & \multirow{2}{*}{$\begin{array}{l}\text { Age Group } \\
\text { (years) }\end{array}$} & \multicolumn{2}{|l|}{ Gymnastics } & \multicolumn{2}{|l|}{ Control } & \multirow[t]{2}{*}{$p$} \\
\hline & & Mean $\left(\mathrm{dp}^{1}\right)$ & Median $\left(\mathrm{IQ}^{2}\right)$ & Mean (dp) & Median (IQ) & \\
\hline \multirow[t]{2}{*}{ Atttention ( $\mathrm{n}^{\circ}$ of hits) } & $60-69$ & $43.71(3.31)$ & $44.00(5.00)$ & $44.60(4.55)$ & $46.00(6.00)$ & 0.53 \\
\hline & $70-79$ & $44.00(4.61)$ & $45.00(8.25)$ & $41.53(4.67)$ & $42.00(7.00)$ & 0.18 \\
\hline \multirow{2}{*}{$\begin{array}{l}\text { Atttention (second } \\
\text { stores pond) }\end{array}$} & $60-69$ & $1.98(0.38)$ & $1.98(0.51)$ & $1.62(0.36)$ & $1.57(0.56)$ & 0.01 \\
\hline & $70-79$ & $2.09(0.45)$ & $1.95(0.53)$ & $2.01(0.39)$ & $2.00(0.62)$ & 0.94 \\
\hline \multirow{2}{*}{$\begin{array}{l}\text { Pre-motor reaction } \\
\text { time for } \mathrm{EV}^{3}(\mathrm{~ms})\end{array}$} & $60-69^{\#}$ & $329.00(72.32)$ & $333.00(61.50)$ & $328.50(81.96)$ & $314.00(36.00)$ & 0.43 \\
\hline & $70-79$ & $328.20(98.73)$ & $295.00(133.00)$ & $329.40(49.11)$ & $321.00(57.00)$ & 0.97 \\
\hline \multirow{2}{*}{$\begin{array}{l}\text { Motor reaction time } \\
\text { for } \mathrm{EV}^{3}(\mathrm{~ms})\end{array}$} & $60-69$ & $305.40(75.61)$ & $301.00(146.00)$ & $308.10(97.50)$ & $319.00(144.00)$ & 0.93 \\
\hline & $70-79$ & $382.30(118.00)$ & $372.50(112.50)$ & $354.10(73.12)$ & $333.00(119.00)$ & 0.45 \\
\hline \multirow{2}{*}{$\begin{array}{l}\text { Pre-motor reaction } \\
\text { time for } \mathrm{EA}^{4}(\mathrm{~ms})\end{array}$} & $60-69$ & $245.90(34.98)$ & $240.00(46.50)$ & $264.70(54.06)$ & $255.00(73.00)$ & 0.25 \\
\hline & $70-79^{\#}$ & $316.90(148.00)$ & $247.50(183.50)$ & $284.40(65.49)$ & $292.00(121.00)$ & 0.94 \\
\hline \multirow{2}{*}{$\begin{array}{l}\text { Motor reaction time } \\
\text { for } \mathrm{EA}^{4}(\mathrm{~ms})\end{array}$} & $60-69$ & $259.80(72.52)$ & $275.00(122.00)$ & $282.50(88.37)$ & $289.00(141.00)$ & 0.43 \\
\hline & $70-79^{\#}$ & $327.60(112.90)$ & $315.00(152.50)$ & $310.80(121.42)$ & $273.01(119.00)$ & 0.71 \\
\hline \multirow[t]{2}{*}{ Field of view (degrees) } & $60-69$ & $132.30(15.58)$ & $133.90(27.30)$ & $136.80(15.92)$ & $132.83(22.00)$ & 0.43 \\
\hline & $70-79$ & $118.30(16.93)$ & $121.70(25.30)$ & $123.00(22.34)$ & $117.40(41.40)$ & 0.56 \\
\hline \multirow{2}{*}{$\begin{array}{l}\text { Tracking deviation }{ }^{5} \text { (with } \\
\text { out unit) }\end{array}$} & $60-69^{\#}$ & $11.30(3.50)$ & $10.90(5.50)$ & $9.35(2.75)$ & $8.30(4.10)$ & 0.16 \\
\hline & $70-79^{\#}$ & $13.48(4.69)$ & $13.50(3.57)$ & $15.57(6.61)$ & $12.90(2.40)$ & 0.68 \\
\hline
\end{tabular}

${ }^{1}$ Standard deviation; $;$ Interquartile range; ${ }^{3}$ Visual stimuli; ${ }^{4}$ Hearing stimuli; ${ }^{5}$ Distributed attention capacity; ${ }^{\#}$ Difference between medians.

\section{DISCUSSION}

The objective of this study was to compare the cognitive and perceptive motor performance of physical activity practicing and non-practicing elderly, considering some variables, which may influence this result. In this study, the performance of both groups was similar, including means and medians for the CG, in some variables (mainly for attention, $p<0.01$ ). Thus, it is accepted the interpretation that physical activity can generate benefits to the cognition of older people, but it can't be neglected the existence of other factors influencing these performances that are present in the daily life of the elderly.

Indications from the American College of Sports Medicine suggest that the regular practice of physical activity (PA) helps to maintain and stimulate the cognitive domains in the elderly ${ }^{6}$ and may delay the progression of cognitive impairment. However, there is no consensus on the dose needed to achieve these goals ${ }^{6}$. The same authors reinforce that for the effective action of PA in maintaining cognitive performance in the elderly, it is important to ensure that the intervention contemplates and aligns coordinative, aerobic and force stimuli. Even with potential results when such stimuli are combined with mental training ${ }^{22}$.

Regarding regular PA, a review of the literature ${ }^{2}$ shows that better performances of cognitive functions occur in elderly with better aerobic capacity. In this study, only active physical activity levels were considered through the IPAQ for the characterization 
of the active groups without evaluating effectively the aerobic capacity of the evaluated individuals. Moreover, the literature indicates only the domain "level of leisure physical activity" as a factor most related to the functional aptitude of the elderly ${ }^{23}$, which makes us reflect on the dose / response of physical activity necessary to positively influence the cognition of these individuals. When considering the time of each gym class, 50 minutes, it is assumed that the weekly frequency of classes to positively benefit the cognition should be three classes and not two, as in this study. However, this assumption has not been analyzed in this work.

In view of the similarity in the psychomotor performance of the elderly, it is possible to emphasize the possibility of not having dedicated a level of attention necessary to the activities during the classes. In gymnastics groups, besides the high number of participants, during the classes (close to one hundred participants / class), there was no measurement of the exercise intensity, which may have affected the results. In addition, the literature has shown that exercise protocols that can include challenging coordinative function activities and close to the day-to-day motor requirements associated with training (known as dual tasks) have presented better results to the individuals' cognition when compared to training force or aerobic only $^{22}$. Such statements are in line with findings in the work of Yokoyama et al. ${ }^{4}$ in which when comparing an intervention with aerobic PA and resistance training with an intervention that combined cognitive stimuli, during the practice of $\mathrm{PA}$, it obtained better results for the work of double assignment

Although there is a vast literature on cognitive and emotional correlates of PA and physical fitness, there is a lack of information on how PA affects the biological properties of the human brain ${ }^{24}$. Moreover, studies show that not only the regular practice of PA but also a good cultural and educational level can protect against cognitive deficits in aging ${ }^{24}$. One of the reasons, perhaps, for the lack of difference in cognitive performance between groups may be due to differences in the level of schooling. In CG, there was a higher proportion of older people with a longer formal education, in CG2, for example, $60 \%$ of the group declared to have higher education, in contrast, in GG2 all participants studied up to high $\operatorname{school}(p=0.02)$.

According to Nascimento et. al. ${ }^{25}$, access to schooling serves to improve cognitive function and may also slow mental decline in recent years, creating a cognitive reserve capacity ${ }^{26}$. Moreover, Domiciano et al. ${ }^{27}$ add that the speed of processing, attention, intelligence, executive functions and memory are sensitive to schooling, and their performance increased the longer the schooling process was.

In addition to the level of schooling, other variables may also influence the incidence of cognitive decline in the elderly, for example, economic income. A study by Sposito, Neri and Yassud ${ }^{28}$ with Brazilian elderly identified worse results in cognitive performance for those who received between one and three minimum wages. According to them, the preservation of cognitive function in aging is related to environmental opportunities modulated by socioeconomic aspects. In the present study, GG declared a lower economic income, especially GG1, in which almost $65 \%$ reported a family income of less than three minimum wages $(p<0.001)$. Following the perspective of Nascimento et $\mathrm{al}^{25}$, who evaluated the prevalence and factors associated to cognitive decline in the elderly with low economic status, access to schooling, income and healthy life habits can positively influence the preservation of the cognitive abilities of the elderly.

During aging, there may be a decline in the ability to see from a distance, to distinguish objects, to estimate distances, to perceive depths. This impairment may result in difficulties in the tasks of motor precision, relative position and depth impairing the performance of visuo-perceptive and constructive tasks $^{29}$. Although, according to the authors, most neuropsychological tests that evaluate visuospatial functions also require other cognitive abilities. In the present study, the visual field variable also presented similarity in its results. However, based on the research of Yip et al. ${ }^{30}$, physical exercise may facilitate ocular blood perfusion, decreasing the incidence of glaucoma, and even attenuate visual field loss ${ }^{31}$.

A secondary variable, the tracking deviation, was extracted from the peripheral perception test, 
which measures the assessed attention capacity of the assessed. In this test, the active elderly group (in the first decade) presented better performance ( $p=0.16$ ), suggesting a better ability to distribute attention when asked to perform two simultaneous tasks, but without significant differences. The ease of better distributing attention can be very useful in everyday activities, such as working in hectic or noisy environments, and guiding a car, activities considered difficult for the elderly. It is understood, then, that this supposed superiority of performance can help to keep the practicing individual of PA more socially participatory than those who do not practice physical activity.

Among the limitations of this study there are the differences between level of schooling, social income and non-measurement of the functional ability of the studied group, since it is understood that they can affect the investigated variables. In addition, since this is a cross-sectional research, it is not possible to make a longitudinal evaluation of cause and effect, and the results presented here are subject to other interpretations.

However, the results obtained are a reference for health management, especially physical education

\section{REFERENCES}

1. Spirduso WW. Dimensões do envelhecimento. São Paulo: Manole; 2005.

2. Bherer L, Erickson KL, Liu-Ambrose T. A Review of the effects of physical activity and exercise on cognitive and brain functions in older adults. J Aging Res. 2013;(n. Esp):1-8.

3. Leckie RL, Oberlin LE, Voss MW, Prakash RS, Szabo-Reed A, Chaddock-Heyman L, et al. BDNF mediates improvements in executive function following a 1 -year exercise intervention. Front Hum Neurosc. 2014;8(985):1-12.

4. Yokoyama H, Okazaki K, Imani D, Yamashina Y, Takeda R, Naghavi N, et al. The effect of cognitivemotor dual-task training on cognitive function and plasma amyloid $\beta$ peptide 42/40 ratio in healthy elderly persons: a randomized controlled trial. BMC Geriatr. 2015;15(60):1-10. professionals, in order to sensitize them to look and improve the interventions offered to the elderly, considering the possibility of allying exercises and strategies to the activities performed during the practice of PA. At the social level, the implementation of physical / cognitive exercise programs becomes of important relevance for the improvement of public and collective actions offered to the elderly. Social actions, which stimulate the resumption of studies for the elderly, can be an essential part of the rehabilitation and maintenance of the cognitive functions of the elderly.

\section{CONCLUSION}

This study found no evidence that regular physical exercise can generate some cognitive benefit in healthy older adults when compared to older people who did not practice physical activities regularly. It should be considered that other aspects such as economic income and schooling can influence the cognitive performance of the elderly, overcoming the practice of physical exercises. Other studies that also examine possible cognitive-moderating variables are needed to more accurately show the benefits of aerobic training in promoting cognition of the elderly.

5. Gajewski PD, Falkenstein M. Physical activity and neurocognitive functioning in aging - a condensed updated review. Eur Rev Aging Phys Act. 2016;13(1): 1-7.

6. Chodzko-Zajko WJ, Proctor DN, Fiatarone Singh MA, Minson CT, Nigg CR, Salem GJ, et al. College of Sports Medicine position stand: exercise and physical activity for older adults. Med Sci Sports Exerc. 2009;41(7):1510-30.

7. Samulski DM. Psicologia do esporte. São Paulo: Manole; 2002.

8. Pundlik S, Tomasi M, Luo G. Evaluation of a portable collision warning device for patients with peripheral vision loss in an obstacle course. Invest Ophthalmol Vis Sci. 2015;56(4):2571-9. 
9. Freudenberger P, Petrovic K, Sem A, Töglhofer AM, Fixa A, Hofer E, et al. Fitness and cognition in the elderly: the Austrian stroke prevention study. Neurology. 2016;86(n. Esp):418-24.

10. Young J, Angevaren M, Rusted J, Tabet N. Aerobic exercise to improve cognitive function in older people without known cognitive impairment. Cochrane Database Syst Rev. 2015;22(4):1-141.

11. Desjardins-Crépeau L, Berryman N, Vu TT, Villalpando JM, Kergoat MJ, Li KZ, et al. Physical functioning is associated with processing speed and executive functions in community-dwelling older adults. J Gerontol Ser B Psychol Sci Soc Sci. 2014;69(6):837-44.

12. Benedetti TB, Antunes PC, Rodriguez-Añez CR, Mazo GZ, Petroski EL. Reprodutibilidade e validade do Questionário Internacional de Atividade Física (IPAQ) em homens idosos. Rev Bras Med Esporte. 2007;13(1):11-6.

13. World Health Organization. Global recommendations on physical activity for health [Internet]. Genebra: WHO; 2010 [acesso em 06 jun. 2016]. Disponível em: http://whqlibdoc.who.int/ publications/2010/9789241599979_eng.pdf

14. Folstein MF, Folstein SE, Mchugh PR. Mini-mental state: a practical method for grading the cognitive state of patients for the clinician. J Psychiatr Res. 1975;12(3):189-98.

15. Brucki SMD, Nitrini R, Caramelli P, Bertoluci PHF, Okamoto IH. Sugestão para o uso do Mini-Exame do estado mental no Brasil. Arq Neuropsiquiatr. 2003;61(3b):777-81.

16. Brasil. Ministério da Saúde. Projeto Olhar Brasil: triagem de acuidade visual. Manual de orientação. Brasília, DF: Ministério da Saúde; 2008:

17. Labanca L, Guimarães FS, Costa-Guarisco LP, Couto EAB, Gonçalves DU. Triagem auditiva em idosos: avaliação da acurácia e reprodutibilidade do teste do sussurro. Ciênc Saúde Colet. 2017;22(11):3589-98.

18. Schuhfried G. Teste Cognitivo: Versão 36.00. Lisboa: Mödling; 2005.

19. Schuhfried G, Prieler J. Teste de Reacções Simples e de Escolha: Versão 29.00. Lisboa: Mödling; 2005.

20. Schuhfried G, Prieler J, Bauer W. Teste de Percepção Periférica. Mödling: Paul Gerin Druckerei; 2006.
21. Carvalho A, Rea IM, Parimon T, Cusack BJ. Physical activity and cognitive function in individuals over 60 years of age: a systematic review. Clin Interv Aging. 2014;9(N. Esp):661-82.

22. Biehl-Printes C, Costa A, Sousa PM, Pinheiro V, Terra N. Prática de exercício físico e função cognitivo-motora: uma orientação global no controle dos efeitos do envelhecimento: Estudo de Revisão. Rev Desporto Activ Fís. 2016;8(1):37-54.

23. Cardoso AS, Mazo GZ, Japiassú AT. Relações entre aptidão funcional e níveis de atividade física de idosas ativas. Rev Bras Ativ Físi Saúde. 2008;13(2):84-93.

24. Gordon BA, Rykhlevskaia EI, Brumback CR, Lee Y, Elavsky S, Konopack JF, et al. Neuroanatomical correlates of aging, cardiopulmonary fitness level, and education. Psychophysiology. 2008;45(5):825-38.

25. Nascimento RAS, Batista RTS, Rocha SV, Vasconcelos LRC. Prevalência e fatores associados ao declínio cognitivo em idosos com baixa condição econômica: estudo MONIDI. J Bras Psiquiatr. 2015;64(3):187-92.

26. Bento-Torres NVO, Bento-Torres J, Tomás AM, Costa VO, Corrêa PGR, Costa CNM, et al. Influence of schooling and age on cognitive performance in healthy older adults. Braz J Med Biol Res. 2017;50(4):1-9.

27. Domiciano BR, Braga DKAP, Da Silva PN, Vasconcelos TB, Macena RHM. Escolaridade, idade e perdas cognitivas de idosas residentes em instituições de longa permanência. Rev Neurocienc. 2014;22(3):330-6.

28. Sposito G, Neri AL, Yassuda MS. Advanced Activities of Daily Living (AADLs) and cognitive performance in community-dwelling elderly persons: Data from the FIBRA Study - UNICAMP. Rev Bras Geriatr Gerontol. 2016;19(1):7-20.

29. Ortega LFV, Stort DR, Yassuda MS. Avaliação Neuropsicológica em Idosos. In: Freitas EV, Py L. Tratado de geriatria e gerontologia. $4^{\mathrm{a}}$ ed. Rio de Janeiro: Guanabara Koogan; 2016. p. 1- 20.

30. Yip J, Broadway DC, Luben R, Garway-Heath DF, Hayat S, Dalzell N, et al. Physical activity and ocular perfusion pressure: the EPIC-Norfolk eye study. Investig Ophthalmol Vis Sci. 2011;52(11):8186-92.

31. Yokota S, Takihara Y, Kimura K, Takamura Y, Inatani $\mathrm{M}$. The relationship between self-reported habitual exercise and visual field defect progression: a retrospective cohort studyrf. BMC Ophthalmol. 2016;16(1):1-4. 